\title{
Orthopaedic management of Hurler's disease after hematopoietic stem cell transplantation: a systematic review
}

\author{
Marleen H. van der Linden • Moyo C. Kruyt • \\ Ralph J. B. Sakkers • Tom J. de Koning • \\ F. Cumhur Öner • René M. Castelein
}

Received: 11 October 2010 /Revised: 11 February 2011 /Accepted: 17 February 2011 /Published online: 17 March 2011

(C) The Author(s) 2011. This article is published with open access at Springerlink.com

\begin{abstract}
Objective The introduction of hematopoietic stem cell transplantation (HSCT) has significantly improved the life-span of Hurler patients (mucopolysaccharidosis type I-H, MPS I-H). Yet, the musculoskeletal manifestations seem largely unresponsive to HSCT. In order to facilitate evidence based management, the aim of the current study was to give a systematic overview of the orthopaedic complications and motor functioning of Hurler's patients after HSCT.

Methods A systematic review was conducted of the medical literature published from January 1981 to June 2010. Two reviewers independently assessed all eligible citations, as identified from the Pubmed and Embase databases. A pre-developed data extraction form was used to systematically collect information on the prevalence of radiological and clinical signs, and on the orthopaedic treatments and outcomes.

Results A total of 32 studies, including 399 patient reports were identified. The most frequent musculoskeletal abnormalities were odontoid hypoplasia (72\%), thoracolumbar kyphosis (81\%), genu valgum (70\%), hip dysplasia (90\%)
\end{abstract}

Communicated by: Ed Wraith

Competing interest: None declared.

M. H. van der Linden · M. C. Kruyt $(\bowtie) \cdot$ R. J. B. Sakkers •

F. C. Öner $\cdot$ R. M. Castelein

Department of Orthopaedics, University Medical Center Utrecht, HP G 05.228, Postbus 85500, 3508 GA Utrecht, The Netherlands e-mail: m.c.kruyt@umcutrecht.nl

T. J. de Koning

Department of Metabolic Diseases, University Medical Center Utrecht, Utrecht, The Netherlands and carpal tunnel syndrome (63\%), which were often treated surgically during the first decade of life. The overall complication rate of surgical interventions was $13.5 \%$. Motor functioning was further hampered due to reduced joint mobility, hand dexterity, motor development and longitudinal growth.

Conclusion Stem cell transplantation does not halt the progression of a large range of disabling musculoskeletal abnormalities in Hurler's disease. Although prospective data on the quantification, progression and treatment of these deformities were very limited, early surgical intervention is often advocated. Prospective data collection will be mandatory to achieve better evidence on the effect of treatment strategies.

\section{Introduction}

Hurler's disease (mucopolysaccharidosis type I, MPS I-H) is an autosomal recessive lysosomal storage disease with an estimated incidence of about 1/ 100,000 (Malm et al. 2008b). The disorder is caused by a deficiency of the enzyme $\alpha$-L-iduronidase (IDUA), leading to the cellular accumulation of the glycosaminoglycans (GAGs) dermatan and heparan sulphate. This cellular accumulation, in turn, leads to progressive and generalised cell, tissue and organ dysfunction. If left untreated, patients will die early of cardiopulmonary failure (median age 6.8 years) (Moore et al. 2008). In addition, patients will develop progressive mental retardation, corneal clouding, hepatosplenomegaly and dysostosis multiplex (Cleary and Wraith 1995). Dysostosis multiplex refers to a broad constellation of skeletal abnormalities such as a thickened skull, shortened long bones, odontoid hypoplasia, vertebral abnormalities, ace- 
tabular dysplasia, genu valgum and short/ broad digits (Aldenhoven et al. 2009). These abnormalities presumably arise from a lack of primary ossification at several predeliction sites, a lack of secondary bone remodelling, and dysfunction of ligamentous structures and joint capsules (Field et al. 1994). Histological examination of growth plates revealed swollen vacuole-filled chondrocytes, architectural irregularities, and failure of cartilage mineralization (Silveri et al. 1991). The exact pathophysiological mechanism underlying the bony abnormalities in Hurler's disease remains unclear, however.

The introduction of hematopoietic stem cell transplantation (HSCT) in 1981 by Hobbs has significantly improved the survival and disease progression of Hurler patients (Hobbs 1981). Following successful engraftment, the donor cells provide a natural source of the deficient enzyme, which results in improved cardiopulmonary symptoms, decreased hepatosplenomegaly and an improved neurodevelopmental status (Peters and Steward 2003; Souillet et al. 2003; Hugh-Jones 1986). As a result, treated patients now survive into adulthood. Yet, the majority of the musculoskeletal problems seem largely unresponsive to HSCT, presumably due to insufficient penetration of the donor enzyme in the skeletal tissues (Breider et al. 1989).

Due to the increased life expectancy of Hurler patients, and the limited response of their musculoskeletal abnormalities to HSCT, orthopaedic problems become relevant in the follow-up of these patients. The majority of Dutch Hurler patients are treated at our institution, and orthopaedic questions regarding the optimal treatment of these disabling musculoskeletal abnormalities have accumulated. Although the literature and the worldwide MPS I registry (Pastores et al. 2007) provide some answers, a systematic overview of the prevalence, clinical course and treatment of the various orthopaedic manifestations of Hurler's disease is currently lacking. Therefore, the objective of this study was to provide a systematic review on the musculoskeletal manifestations of Hurler's disease after HSCT, with emphasis on the orthopaedic treatment and outcome. Additionally, information on aspects of motor functioning such as gait/mobility, motor skills, joint range of motion and longitudinal growth was systematically collected.

\section{Methods}

Search strategy

An electronic search of the literature published from January 1981 to June 2010 was conducted in Pubmed and Embase, by using MeSH (Medical Subject Heading, Medline) and EMBASE terms, as well as free text words. The search included the terms Hurler, mucopolysaccharidosis type I, MPS I, iduronidase deficiency, orthopaedic, orthopedic, dysostosis multiplex, musculoskeletal, hip, spine, knee, joint, bones, myelopathy, kyphosis, genu valgum, carpal tunnel syndrome, trigger finger, odontoid, growth, height and motor development. Two reviewers (MV and MK) independently assessed the titles and abstracts of all eligible citations to determine if they met the inclusion criteria. Selected articles were then evaluated in full text by the same two reviewers. Additional articles were sought by reference tracking. Disagreements were resolved by means of discussion.

Inclusion and exclusion criteria

The search strategy was confined to patients with Hurler's disease after hematopoietic stem cell transplantation (HSCT) in combination with a description of the musculoskeletal manifestations and/or the topics: gait, motor skills, joint range of motion (ROM), longitudinal growth and neurological symptoms. Only original articles published after 1981 were selected (the introduction of HSCT for MPS by Hobbs (Hobbs 1981)). All languages were included. Case reports and selected patient populations were reviewed for treatment options only. Papers were excluded if patients were not treated with HSCT, or if we remained unsure about previous HSCT after contacting the authors.

\section{Data extraction}

A pre-developed data extraction form was used to systematically collect all relevant information from the articles. All data were scored in relation to the patient's age and duration of follow-up after HSCT. The orthopaedic aspects contained the radiological and clinical signs of spinal involvement, hip dysplasia, genu valgum, carpal tunnel syndrome and trigger fingers. In addition, all available information on orthopaedic treatments and outcomes was collected. A surgical complication or adverse outcome was defined as the need for a re-operation, a correction that was judged insufficient by the authors (e.g. tibio-femoral angle $>7^{\circ}$, Odunusi et al. 1999), or the absence of an objective improvement in disease symptoms.

Data analysis

The average prevalence of the radiological and clinical signs of Hurler's disease was calculated by pooling all reported cases per topic (so called patient reports). In addition, weighted averages of the age at HSCT and duration of follow-up after HSCT were calculated. A similar method was used to pool all data on treatment options and outcome. The number of reports that were 
available for the calculation of the average age at HSCT and follow-up after HSCT was usually somewhat smaller compared to the number of available reports on prevalence (data not shown). For the prevalence data, only papers on non-selected patient cohorts were included. As a consequence, five papers were excluded from this analysis; three on CTS (17 patients referred for CTS diagnostics), one on kyphosis (one patient referred for anterior fusion) (Dalvie et al. 2001), and one on linear growth (eight patients treated with growth hormone therapy) (Polgreen et al. 2009).

When reviewing the included articles, 5 studies stated that similar patients were included in multiple papers. The number of patients that were reported twice ranged from 26. Yet, the topics and duration of follow-up differed across the studies. All other included papers were analysed for potential patient overlap as well. As shown in Table 1, a large number of studies originated from a limited number of institutions. After careful comparison, no more than two papers with potential patient overlap per topic were identified. Because these papers contained unique and relevant data, all selected patient reports were included for further evaluation.

\section{Results}

\section{Description of studies}

A total of 32 studies (31 case series and one case report) published between 1993 and 2009 were included (see Fig. 1 for flow chart and Table 2). These studies described a total of 399 patient reports. The vast majority of studies (29) were longitudinal and of retrospective nature. A total of 26 studies described only Hurler patients, the other six studies described mixed patient populations. The average age of the patients at HSCT was $18.8 \pm 7.0$ months (25 studies, $\mathrm{n}=348$ patients, range across studies $13-48$ months). The average duration of follow-up was $73.3 \pm 35.4$ months after HSCT (23 studies, $\mathrm{n}=321$ patients, range across studies 10.5-134.4 months). The donor source that was used for HSCT treatment was described by 16 studies; eight had included multiple donor types, four used cord blood transplantations only, three were confined to unrelated donors, and one to related donors. The success rate of HSCT was described by 14 papers, with full engraftment at the first attempt in on average $76 \%$ of the cases (range 47 $100 \%)$. In the following sections, the motor functioning/ longitudinal growth and musculoskeletal manifestations of Hurler's disease will be addressed separately (section 3.2 and 3.3 respectively). Note that prevalence data were calculated based on subgroup analyses, with average group sizes of 55 patients (range 21-107) for motor functioning (Table 3A), 48 (range 7-103) for the musculoskeletal manifestations (Table 3B), and 88 (range 7-170) for the surgical interventions (Table 3C).

Motor functioning and longitudinal growth of Hurler patients after HSCT

With increasing life expectancy in Hurler's disease, recent research activities have focussed their attention on everyday functioning. Gait and independent mobility are important
Table 1 Institutes at which the included studies were conducted

\begin{tabular}{lll}
\hline Origin of included studies & $\begin{array}{l}\text { Total number } \\
\text { of articles }\end{array}$ & $\begin{array}{l}\text { Total number } \\
\text { of patients }\end{array}$ \\
\hline University of Minnesota, Minneapolis, U.S.A. & 8 & 210 \\
University of North Carolina, Chapel Hill, U.S.A & 3 & 41 \\
Westminster Children's Hospital, London, U.K. & 3 & 17 \\
Our Lady's Hospital for Sick Children, Dublin, Ireland & 2 & 31 \\
Royal Manchester Children's Hospital, Manchester, U.K. & 2 & 22 \\
Hôpital Debrousse, Lyon, France & 2 & 20 \\
Karolinska University Hospital, Stockholm, Sweden & 2 & 10 \\
Children's Hospital and Franciscan Hospital for children, Boston, U.S.A. & 2 & 2 \\
Duke University Medical Center, Durham, U.S.A. & 1 & 17 \\
University of Kentucky Medical Center, Lexington, U.S.A. & 1 & 11 \\
University of California, San Francisco, U.S.A. & 1 & 7 \\
Children's Hospital, Hannover Medical School, Hannover, Germany & 1 \\
Children's Hospital, North Adelaide, Australia & 1 & 5 \\
Hôpital Neurologique, Lyon, France & 1 & 3 \\
University of Western Ontario, London, Canada & 1 & 1 \\
Pellenberg University Hospital, Lubbeek, Belgium & 1 & 1 \\
Total & 32 & 1 \\
\hline
\end{tabular}


Fig. 1 Flow chart of included studies

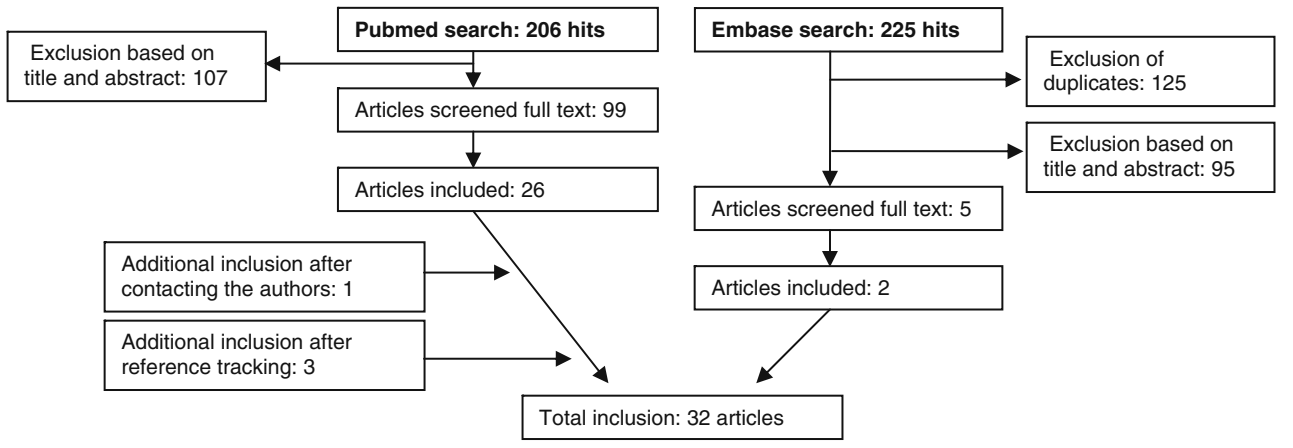

aspects of everyday motor functioning. A total of nine studies, including 81 patients investigated gait in Hurler's disease (see also Table 3A). All of these studies addressed one of three aspects of gait: 1) development of independent walking in toddlers, 2) quality of gait, and 3) independent gait and mobility in late childhood/ adolescence. With respect to independent walking, four studies reported a delayed onset (Hugh-Jones 1986; Dusing et al. 2007a; Ringden et al. 2006; Dusing et al. 2007b). This developmental delay was attributed to limited practice during hospitalisation for HSCT, in addition to orthopaedic abnormalities (Dusing et al. 2007a). The second aspect of gait, quality of gait, has recently been addressed by Dusing et al. in a group of 18 patients (Dusing et al. 2007a). The patients had reduced walking speed, shortened step length, and increased energy expenditure early in life. Yet, walking speed and step length normalised by the age of 4 years. The third aspect of gait concerned the preservation of independent gait (see also Table 3A). While the majority of patients remained mobile, independent unaided gait was lost in 12 patients $(24.5 \%)$, at a mean follow-up of 72.6 months after HSCT, predominantly due to orthopaedic complications such as severe genu valgum and hip dislocation.

Other aspects that contribute to motor functioning are the development of gross and fine motor skills. These were generally studied on a group level, using developmental scales such as the Vineland Adaptive Behavior Scales (VABS) (Bjoraker et al. 2006), Peabody Developmental Motor Scales, edition 2 (PDMS-2) (Dusing et al. 2007a; Dusing et al. 2007b; Dusing et al. 2005), Denver Developmental Screening Test (DDST) (Lucke et al. 2007), and the more recently developed MPS-PPM (MPS physical performance measure) (Dumas et al. 2004). Evaluation of these five studies, including a total of 63 patients, showed that Hurler patients were limited in their gross motor development and had mild to pronounced motor retardation between 0 and 4 years of age, when compared to age-referenced controls. However, the limitations in a group of 41 treated Hurler patients were milder as compared to a cross-sectional group of 43 non-treated patients (Bjoraker et al. 2006). Not surprisingly, the degree of motor development was associated with the age and developmental status of the patients at the time of HSCT, such that the younger and less affected patients had a better developmental outcome (Bjoraker et al. 2006).

On the topic of fine motor skills, specifically hand dexterity, individual patient data were available (see Table 3A). Although age-referenced hand function improved after HSCT treatment (Hugh-Jones 1986; Lucke et al. 2007), $88.5 \%$ of the patients still showed impairments in comparison to healthy children. These impairments were partly caused by comorbidities such as CTS (Malm et al. 2008b), trigger fingers (Weisstein et al. 2004) and spinal cord compression (Kachur and Del Maestro 2000), and for the other part by bony abnormalities such as broad stubby digits.

Limitations in joint range of motion (ROM), especially of the upper extremity, were another main feature of Hurler's disease (prevalence 94.5\%, see Table 3A). Although positive effects of HSCT on joint ROM were consistently reported, joint mobility in treated Hurler patients remained limited (Field et al. 1994; Hugh-Jones 1986; Weisstein et al. 2004; Fleming et al. 1998; Guffon et al. 1998). Fixed flexion contractures of the lower extremity were occasionally reported in the older literature, when surgical interventions of progressive hip subluxation and genu valgum were postponed (Field et al. 1994).

Although some authors have optimistically reported normalised longitudinal growth following HSCT (Hugh-Jones 1986), growth rates appeared compromised at long term follow-up. A total of nine studies, including 107 patients, have reported growth details. A height below 2SD of the average is generally considered abnormal. Information on the number of patients shorter than $-2 \mathrm{SD}$ was provided by 58 patient reports. A total of $51.7 \%$ of these patients had short stature, with a mean follow-up of 80.2 months after HSCT. The linear growth of Hurler patients was associated with the age at HSCT (Souillet et al. 2003; Polgreen et al. 2008; Vellodi et al. 1997), such that a younger age at HSCT resulted in a larger height. High enzyme levels following HSCT, and conditioning regimens for HSCT without total body irradiation were also associated with a larger height (Polgreen et al. 2008). In general, the growth rate of Hurler patients remained 
Table 2 Specifications of the included articles

\begin{tabular}{|c|c|c|c|c|c|}
\hline $\begin{array}{l}\text { Year of } \\
\text { publication }\end{array}$ & $\begin{array}{l}\text { First } \\
\text { author }\end{array}$ & $\begin{array}{l}\text { Number of } \\
\text { Hurler patients }\end{array}$ & $\begin{array}{l}\text { Age at HSCT } \\
\text { (months) }\end{array}$ & $\begin{array}{l}\text { Follow up since } \\
\text { HSCT (months) }\end{array}$ & Major topics \\
\hline 1986 & Hugh-Jones & 5 & 19.6 & 37.8 & Kyphosis, gait, hand dexterity, joint ROM, growth \\
\hline 1993 & Belani & 30 & & & $\begin{array}{l}\text { C1-2 instability, odontoid dysplasia, cord compression, } \\
\text { neurological symptoms }\end{array}$ \\
\hline 1993 & Hopwood & 3 & 13 & $>120$ & $\begin{array}{l}\text { Kyphosis, hip dislocation, genu valgum, CTS, gait, joint ROM } \\
\text { and surgical procedures } *\end{array}$ \\
\hline 1994 & Bona & 1 & & & CTS (surgery) \\
\hline 1994 & Field & 11 & 19.5 & 111 & $\begin{array}{l}\text { Kyphosis, hip dysplasia, genu valgum, CTS, joint ROM, growth } \\
\text { and surgical procedures }\end{array}$ \\
\hline 1996 & Masterson & 8 & 9 & 28 & Hip dysplasia (surgery), gait \\
\hline 1996 & Tandon & 12 & 16 & 54 & $\begin{array}{l}\text { C1-2 instability, odontoid dysplasia, soft tissue deposition, cord } \\
\text { compression, vertebral abnormalities, kyphosis (surgery), } \\
\text { scoliosis, disc abnormalities, spondylolisthesis, neurological } \\
\text { symptoms }\end{array}$ \\
\hline 1997 & Vellodi & 10 & 17 & 134.4 & $\begin{array}{l}\text { C1-2 instability, odontoid hypoplasia, soft tissue deposition, } \\
\text { cord compression, kyphosis, hip dysplasia, gait, motor } \\
\text { development, hand dexterity, growth and surgical procedures }\end{array}$ \\
\hline 1998 & Flemming & 11 & 20 & 60 & Joint ROM \\
\hline 1998 & Guffon & 9 & & 60 & $\begin{array}{l}\text { Kyphosis, hip dysplasia, genu valgum, CTS, joint ROM, growth } \\
\text { and surgical procedures }\end{array}$ \\
\hline 1998 & van Heest & 15 & 21 & & CTS and trigger finger surgery \\
\hline 1999 & Odunusi & 17 & 19 & & Genu valgum (surgery) \\
\hline 2000 & Hite & 8 & 20 & 104.4 & Odontoid hypoplasia, soft tissue deposition, cord compression \\
\hline 2000 & Kachur & 1 & 24 & 72 & $\begin{array}{l}\text { Cord compression (surgery), soft tissue deposition, kyphosis, } \\
\text { genu valgum, neurological symptoms, hand dexterity, muscle } \\
\text { strength }\end{array}$ \\
\hline 2001 & Dalvie & 1 & 48 & 12 & Kyphosis (surgery) \\
\hline 2003 & Souillet & 11 & 24.2 & 90 & $\begin{array}{l}\text { C1-2 instability, kyphosis, scoliosis, genu valgum, hip } \\
\text { dysplasia, CTS, joint ROM, muscle strength, growth and } \\
\text { surgical procedures }\end{array}$ \\
\hline 2004 & Dumas & 1 & & & Gait, motor development \\
\hline 2004 & Staba & 17 & 18 & 54 & Kyphosis, growth and surgical procedures \\
\hline 2004 & Weisstein & 7 & 20 & 55.2 & $\begin{array}{l}\text { C1-2 instability, soft tissue deposition, vertebral and disc } \\
\text { abnormalities, kyphosis, hip dysplasia, genu valgum, CTS and } \\
\text { trigger fingers, neurological symptoms, hand dexterity, joint } \\
\text { ROM and surgical procedures }\end{array}$ \\
\hline 2005 & Dusing & 2 & 22.5 & 10.5 & Motor development, hand dexterity, kyphosis, hip dislocation \\
\hline 2005 & van Meir & 1 & & & CTS and kyphosis surgery \\
\hline 2006 & Bjoraker & 41 & 21.7 & 67.2 & Motor development \\
\hline 2006 & Ringdén & 4 & $<20$ & & $\begin{array}{l}\text { Kyphosis (surgery), hip dislocation, gait, neurological } \\
\text { symptoms }\end{array}$ \\
\hline 2007 & Dusing & 21 & 17.1 & 16.2 & Motor development, genu valgum \\
\hline 2007 & Dusing & 18 & 18.8 & 29.9 & Gait \\
\hline 2007 & Khanna & 43 & 19 & 103.2 & CTS (surgery) \\
\hline 2007 & Lucke & 5 & 25 & 46 & Motor development, hand dexterity \\
\hline 2008 & Malm & 6 & 18 & 67.2 & $\begin{array}{l}\text { Hip dysplasia, CTS, neurological symptoms, hand dexterity, } \\
\text { growth and surgical procedures }\end{array}$ \\
\hline 2008 & Polgreen & 48 & 20 & 83 & Growth \\
\hline 2008 & Taylor & 23 & 9.4 & 102 & $\begin{array}{l}\text { Kyphosis, scoliosis, genu valgum, hip dysplasia, gait, joint } \\
\text { ROM, muscle strength, growth and surgical procedures }\end{array}$ \\
\hline 2009 & Polgreen & 8 & & & Kyphosis, genu valgum and surgical procedures \\
\hline 2009 & Rebello & 1 & & & Hip dysplasia (surgery) \\
\hline
\end{tabular}

$\mathrm{HSCT}=$ hematopoietic stem cell transplantation, $\mathrm{ROM}=$ range of motion, $\mathrm{CTS}=$ carpal tunnel syndrome

* Surgical procedures are not further specified in the current table 
Table 3 A, B, C. Motor functioning, musculoskeletal manifestations, and surgical interventions in Hurler's disease after HSCT treatment

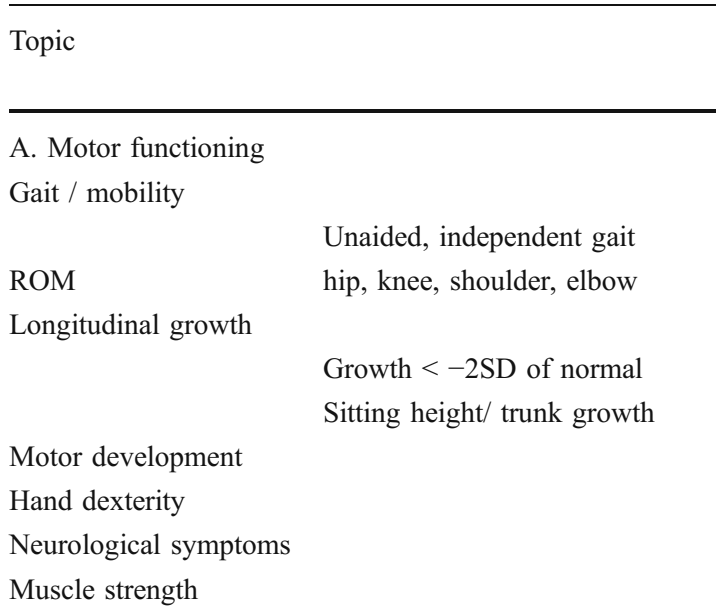

Total number
of papers

Total number of patients

\section{Affected}

patients $\mathrm{N}(\%)$
Age at HSCT

(months)
Follow-up after HSCT (months)

B. Musculoskeletal manifestations

I. Radiological signs

X-ray of cervical spine

$$
\begin{aligned}
& \text { C1-2 instability } \\
& \text { Odontoid hypoplasia }
\end{aligned}
$$

70

60

MRI of cervical spine

Soft tissue deposition
around odontoid
Spinal cord compression
Ligamentous hypertrophy

X-ray or MRI of thoracolumbar spine

Vertebral abnormalities

Kyphosis

Scoliosis

Spondylolisthesis

Disc abnormalities

X-knee

X-hip

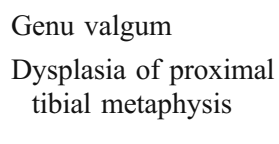

Hip dysplasia
Hip dislocation/ (sub)luxation

II. Hand involvement

Carpal tunnel syndrome

Trigger fingers

C. Surgical interventions

Treatment

Cervical fusion

Spinal cord decompression

Thoracolumbar spinal fusion

Knee surgery

Hip containment surgery

Carpal tunnel release

Trigger finger release

81
49
55
107
58
21
63
26
61
45

*

20.0

72.6

$52(94.5)$

20.6

92.0

30 (51.7)

20.0

80.2

$*$

$*$

$23(88.5) \quad 20.8 \quad 50.1$

$12(19.7) \quad 20.6 \quad 48.5$

345 
normal for several years, after which it gradually decreased. For example, Vellodi et al. showed that the average height of 10 patients reached -2SD at an age of 6 years (Vellodi et al. 1997). The decreased growth was largely attributable to a reduced trunk growth with an average sitting height below 3SD at 8 years of age, and below 4SD at 12 years of age (corresponding subischial leg length of $0 \mathrm{SD}$ and $-2 \mathrm{SD}$ respectively).

Motor functioning in Hurler's disease was further compromised by neurological comorbidities. A total of seven papers, including 61 patients, documented the neurological status of the patients. Neurological complications were observed in $19.7 \%$ of the patients, consisting of increased intracranial pressure $(n=4)$, a tethered cord $(n=2)$, signs of spinal cord or cauda compression $(n=4)$ and abnormal neurological leg functioning $(n=3)$. Reduced muscle strength was generally not found (Souillet et al. 2003; Field et al. 1994), although one report described mild proximal weakness of the legs (Taylor et al. 2008).

\section{Musculoskeletal manifestations of Hurler's disease - prevalence}

The prevalence of the main orthopaedic and radiological signs of Hurler's disease is depicted in Table 3B. In the following section, these orthopaedic signs will be addressed separately.

Spine Cervical involvement was frequently reported in Hurler's disease. In particular, a failure of ossification of the odontoid process (odontoid dysplasia or hypoplasia), which was identified in $71.7 \%$ of the patients (Vellodi et al. 1997; Belani et al. 1993; Hite et al. 2000; Tandon et al. 1996). Somewhat remarkably, the odontoid dysplasia appeared to respond favourably to HSCT treatment (improvement of moderate/severe to mild dysplasia in 10 patients) (Hite et al. 2000; Tandon et al. 1996). Soft tissue depositions around the odontoid process were found in $85.7 \%$ of the patients, and $31.6 \%$ showed hypertrophy of the longitudinal ligaments (Weisstein et al. 2004; Kachur and Del Maestro 2000; Vellodi et al. 1997; Hite et al. 2000; Tandon et al. 1996). These cervical manifestations may result in potentially life-threatening atlantoaxial instability and spinal cord compression. Yet, in the Hurler population these symptoms were relatively rare. Atlantoaxial instability, based on flexion-extension X-rays, was identified in $20 \%$ of the patients (Souillet et al. 2003; Weisstein et al. 2004; Vellodi et al. 1997; Belani et al. 1993; Tandon et al. 1996). Cervical spinal cord compression, predominantly based on MRI imaging, was observed in only 3.4\% ( 2 cases) (Kachur and Del Maestro 2000; Vellodi et al. 1997; Belani et al. 1993; Hite et al. 2000; Tandon et al. 1996).
One of the other key features of spinal involvement in Hurler's disease is the thoracolumbar kyphosis or gibbus deformity, which was observed in $81 \%$ of the patients (see also Table 3B). The thoracolumbar kyphosis usually develops at the level of L1-L2, and has been observed as early as birth (Cleary and Wraith 1995; Dusing et al. 2005). Failure of ossification of the anterior superior aspect of the vertebral body, i.e. beaking, was observed in $93.3 \%$ of the patients (Table 3B). Spondylolisthesis was frequently observed as well, with thinning and elongation of the pedicles, hypoplasia of the facet joints and scalloping of the posterior border of the vertebrae (Weisstein et al. 2004; Tandon et al. 1996). Only two studies reported disc space narrowing (three affected patients, prevalence 30\%). Thoracolumbar spinal cord compression was also rare and documented for two patients (prevalence 3.4\%) (Weisstein et al. 2004; Tandon et al. 1996). Although not as common as kyphosis, scoliosis was relatively common in Hurler patients as well (prevalence $32.6 \%$ ). In 53\% of the scoliosis patients, scoliosis was observed in combination with kyphosis.

Hips Another predeliction site for the failure of primary ossification in Hurler's disease was the acetabulum, resulting in acetabular dysplasia with subsequent hip lateralisation and (sub)luxation. A total of eight articles including 67 patients addressed acetabular dysplasia, with a prevalence of $89.6 \%$. Early arthrography consistently revealed a non-ossified cartilaginous acetabular roof, with a centrally ossified femoral head (Field et al. 1994; Taylor et al. 2008; Masterson et al. 1996), sometimes in combination with an eversion of the acetabular labrum (Masterson et al. 1996). Acetabular dysplasia was not necessarily associated with dislocation of the hip (dislocation present in $40.6 \%$ of the patients). In order to quantify the degree of acetabular dysplasia, several methods have been used. Especially for patients undergoing surgery, measures of the MEA (mean acetabular angle), CEA (centre-edge angle), and the extrusion index have been documented (Weisstein et al. 2004; Taylor et al. 2008; Masterson et al. 1996; Rebello et al. 2009). On average, MEA scores ranged from $36^{\circ}$ pre-operatively to $20^{\circ}$ postoperatively ( $\mathrm{n}=27$ patients). In addition to acetabular dysplasia, coxa valga and thinning of the femoral epiphysis were consistently shown as well $(n=8(100 \%)$ and $n=42$ (100\%) respectively) (Field et al. 1994; Taylor et al. 2008; Masterson et al. 1996).

Knees Failure of ossification was also observed for the lateral margin of the proximal tibial metaphysis, resulting in progressive genu valgum. A total of 103 patient reports on genu valgum showed a prevalence of $69.9 \%$. Genu valgum was usually defined as a tibial femoral shaft angle of $>7^{\circ}$, with an average pre-operative angle of $17.9^{\circ}$ (angular data 
for only $n=13$ patients). It was predominantly identified between 2 and 5 years of age (Odunusi et al. 1999). Spontaneous regression was not observed, and progression has been associated with severe functional limitations (Field et al. 1994).

Hands The prevalence of carpal tunnel syndrome (CTS), as identified from seven papers including 90 patients, was $63.3 \%$ (see Table 3B). The compression of the median nerve was caused by GAG deposition in the flexor retinaculum, in combination with skeletal deformities (Field et al. 1994; Van Heest et al. 1998). The development of CTS was directly associated with the age of the patients at HSCT, with each year prior to HSCT leading to a $58 \%$ increase in the risk of developing CTS (Khanna et al. 2007). The development of CTS seemed also related to the enzyme activity after HSCT, since all patients with low enzyme activity in the study of Khanna et al. developed CTS (Khanna et al. 2007). Additional limitations in hand dexterity might originate from the development of trigger fingers with flexion deformities. Reports on the prevalence of trigger fingers were limited (one paper, seven patients) with a prevalence of 57.1\% (Weisstein et al. 2004).

\section{Musculoskeletal manifestations of Hurler's disease - orthopaedic management}

Most authors recommended early surgical intervention in Hurler's disease (Field et al. 1994; Weisstein et al. 2004; Taylor et al. 2008; Masterson et al. 1996; Odunusi et al. 1999). Yet, timing and type of surgery greatly varied. Table 3C shows the prevalence of the various surgical interventions. Table 4 summarizes their subtypes and outcomes. The average age at which Hurler patients underwent surgery is depicted in Table 5. A total of 252 reports on orthopaedic surgeries were identified, with 163 reports on treatment outcome. In the past, cardiopulmonary complications such as difficult intubation and coronary obstruction have led to several intra-operative deaths in Hurler patients (Belani et al. 1993). Improved anaesthetic techniques and increased knowledge have reduced the risk of such intra-operative complications (Ard et al. 2005; Martins et al. 2009). With regard to the orthopaedic outcome, the overall complication rate was 13.5\% (22 affected patients). Yet, some treatments had complication rates up to $42.9 \%$ (thoracolumbar bracing, $n=6 /$ isolated femoral osteotomy, $\mathrm{n}=6$ ) and 56.3\% (epiphyseal stapling, $n=9)$. Surgical failure was generally not due to non-union, as bone-healing showed normal callus formation and union (Field et al. 1994). In the following section, the subtypes and outcomes of the various surgical interventions will be further elaborated on.
Spine Surgical treatments for cervical instability and spinal cord compression were relatively rare in Hurler's disease, with a prevalence of $11.1 \%$ and $17.6 \%$ respectively (see also Table $3 \mathrm{C}$ ). In the case of cervical instability, both occiput-C2 and C1-C2 fusions were performed (see Table 4). The outcome was discussed for only one patient with a temporary non-union following an occiput-C2 fusion, due to suboptimal immobilisation after surgery (Minerva brace) (Weisstein et al. 2004). For cervical cord compression, successful laminectomies have been described. Yet, further details on the surgical technique were lacking.

The orthopaedic treatment of thoracolumbar kyphosis appeared to be contentious with respect to both timing and type of intervention. For mild cases of kyphosis (i.e an angle below $40^{\circ}$ ) treatment was often postponed. Spontaneous improvement of mild kyphosis was observed in $15.2 \%$ of the patients ( 7 cases) (Weisstein et al. 2004; Staba et al. 2004). In addition, 21 cases of stable mild kyphosis were described (Souillet et al. 2003; Weisstein et al. 2004; Taylor et al. 2008; Staba et al. 2004). It must be mentioned, however, that follow-up periods for these patients did not extend into adolescence. In the case of progression or anticipated progression of kyphosis, some authors have attempted bracing (Souillet et al. 2003; Guffon et al. 1998; Taylor et al. 2008; Tandon et al. 1996). The outcome of bracing was variable, with ongoing progression of the kyphotic angle in $42.9 \%$ of the patients (six cases, see also Table 4).

When the kyphotic angle progressed, surgical intervention was often required. The pre-operative Cobbs angle was on average $58.8^{\circ}$ (angular data for only 4 patients). Furthermore, spinal cord compression, as observed in two cases, was a clear indication for surgery. Spinal fusion was performed in $32.4 \%$ of the patients, with an average follow-up duration of 86 months after HSCT (see Table 3C). The average age at spinal fusion was 5.9 years (see Table 5). For the surgical correction of kyphosis, both anterior and posterior short segment fusions were described, as well as their combination. As appears from Table 4, no adverse outcomes were reported for any of the techniques.

Hips Hip containment surgery as a treatment for hip dysplasia was common in Hurler patients (prevalence $45.5 \%$, see Table 3C). The average age at surgery was 7.4 years (see Table 4 and 5). Several techniques have been attempted, such as an isolated femoral osteotomy, an isolated pelvic osteotomy and a combination of both techniques. As is shown in Table 4, isolated femoral osteotomies have resulted in a large percentage of failure $(42.9 \%, n=6)$ due to the absence of acetabular remodelling after surgery, requiring revision surgery (Field et al. 1994; Vellodi et al. 1997; Taylor et al. 2008). Therefore, a 
Table 4 Orthopaedic treatments and outcome

\begin{tabular}{|c|c|c|c|c|c|}
\hline $\begin{array}{l}\text { Orthopaedic } \\
\text { treatment for }\end{array}$ & $\begin{array}{l}\text { Number of } \\
\text { articles }\end{array}$ & $\begin{array}{l}\text { Number of patients } \\
\text { operated on }\end{array}$ & $\begin{array}{l}\text { Number of patients with } \\
\text { reported outcome }\end{array}$ & $\begin{array}{l}\text { Complication } \\
\text { rate }\end{array}$ & $\begin{array}{l}\text { Description of } \\
\text { complication }\end{array}$ \\
\hline \multicolumn{6}{|l|}{ Cervical instability } \\
\hline $\mathrm{O}-\mathrm{C} 2$ fusion & 3 & 3 & 1 & $100 \% *$ & Non- union (Minerva brace) \\
\hline C1-2 fusion & 1 & 1 & & & \\
\hline Cervical fusion, NFS & 1 & 1 & & & \\
\hline Total & 5 & 5 & & & \\
\hline \multicolumn{6}{|l|}{ Cord compression } \\
\hline Cervical laminectomy & 2 & 2 & 2 & $0 \%$ & \\
\hline Thoracal laminectomy & 1 & 2 & & & \\
\hline Total & 3 & 4 & & & \\
\hline \multicolumn{6}{|l|}{ Kyphosis } \\
\hline Anterior fusion & 2 & 3 & 1 & $0 \% *$ & \\
\hline Posterior fusion & 3 & 12 & 6 & $0 \%$ & \\
\hline Ant + post fusion & 1 & 1 & & & \\
\hline Spinal fusion, NFS & 9 & 39 & 6 & $0 \%$ & \\
\hline Bracing & 5 & 16 & 14 & $42.9 \%$ & Progression of kyphosis \\
\hline Total & 15 & 58 & & & \\
\hline \multicolumn{6}{|l|}{ Genu valgum } \\
\hline Epiphyseal stapling & 5 & 22 & 16 & $56.3 \%$ & $\begin{array}{l}\text { Staple dislodgement/ } \\
\text { Relapse after removal }\end{array}$ \\
\hline Hemi-epiphysiodesis & 1 & 2 & & & \\
\hline Osteotomy & 1 & 1 & & & \\
\hline Surgery, NFS & 1 & 26 & & & \\
\hline Total & 9 & 51 & & & \\
\hline \multicolumn{6}{|l|}{ Hip dysplasia } \\
\hline Isolated femoral osteotomy & 5 & 16 & 14 & $42.9 \%$ & No acetabular remodelling \\
\hline Isolated pelvic osteotomy & 4 & 8 & 8 & $0 \%$ & \\
\hline Femoral+pelvic osteotomy & 5 & 19 & 17 & $0 \%$ & \\
\hline Surgery, NFS & 2 & 39 & & & \\
\hline Total & 15 & 46 & & & \\
\hline \multicolumn{6}{|l|}{ Carpal tunnel syndrome } \\
\hline Soft tissue release & 13 & 80 & 70 & $1.4 \%$ & No improvement of NCV \\
\hline \multicolumn{6}{|l|}{ Trigger digits } \\
\hline Soft tissue release & 3 & 10 & 8 & $0 \%$ & \\
\hline Overall total & 63 & 252 & 163 & $13.5 \%$ & \\
\hline
\end{tabular}

$\mathrm{NFS}=$ not further specified, $\mathrm{NCV}=$ nerve conduction velocity

* Note that these percentages are based on a single patient report

combination of a pelvic and femoral osteotomy was attempted instead, in 19 patients. The latter technique showed good results, with no reported adverse outcomes (Souillet et al. 2003; Weisstein et al. 2004; Taylor et al. 2008; Masterson et al. 1996). More recently, it has been shown that an isolated pelvic osteotomy without an additional femoral osteotomy, performed in 8 patients, was sufficient to contain proper femoral head coverage as well (Ringden et al. 2006; Weisstein et al. 2004; Taylor et al. 2008; Masterson et al. 1996).
Knees Genu valgum usually occurred between 2 and 5 years of age (Odunusi et al. 1999). Since spontaneous improvement was generally not observed, a surgical correction was carried out in a considerable amount of patients $(36.4 \%$, see Table 3C). The most common type of surgery was a temporary hemi-epiphysiodesis by medial epiphyseal stapling (Table 4), performed at an average age of 7.7 years (Table 5). Complications were reported for $56.3 \%$ of the patients $(n=9)$ (Taylor et al. 2008; Odunusi et al. 1999). The majority of adverse outcomes were related to the dislodge- 
Table 5 Average age of Hurler patients at surgery

\begin{tabular}{llll}
\hline Surgery & $\begin{array}{l}\text { Average age at } \\
\text { surgery (years) }\end{array}$ & $\begin{array}{l}\text { Age range across } \\
\text { studies (years) }\end{array}$ & $\begin{array}{l}\text { Total number of operated } \\
\text { patients with age reference }\end{array}$ \\
\hline Cervical fusion & 9.3 & {$[7-12]$} & 3 \\
Spinal cord decompression & 8 & {$[8]$} & 1 \\
Thoracolumbar spinal fusion & 5.9 & {$[3.5-9.3]$} & 22 \\
Epiphyseal stapling & 7.7 & {$[6.5-11]$} & 9 \\
Hip containment surgery & 7.4 & {$[4.4-8.6]$} & 18 \\
Carpal tunnel release & 5.4 & {$[3.4-9.3]$} & 57 \\
Trigger finger release & 6.9 & {$[6.9]$} & 4 \\
\hline
\end{tabular}

ment of staples due to the use of suboptimal materials (barbed stainless steel), rather than by MPS I disease characteristics. Consequently, no complications have been described after the introduction of new materials (barbed vitallium staples) and the 8-plate (Taylor et al. 2008; Odunusi et al. 1999). Genu valgum was also corrected by a permanent hemi-epiphysiodesis in two patients. Since the outcome of this technique largely depends on the (unpredictable) appendicular growth of Hurler patients after surgery, this technique has become obsolete.

Hands Surgical release of the carpal tunnel, with or without additional tenosynovectomy of the flexor retinaculum, was the most often reported musculoskeletal intervention in Hurler patients (80 patient reports, Table 4; prevalence of $56 \%$, Table 3C). A total of 70 patient reports on the outcome of surgical release for CTS were identified (see Table 4). Following surgery, muscle strength and EMG findings considerably improved. Although these beneficial effects have even been described for patients with already severe nerve compression, surgical release presumably elicits better results if done early (Van Heest et al. 1998). A lack of EMG improvements following surgery was reported only once $(1.4 \%$ of the cases (Vellodi et al. 1997)).

Trigger fingers were reported less frequently, with only ten descriptions of a surgical release in the current literature (see Table 4). All trigger finger releases were performed in conjunction with a CTS release. The techniques used, were a resection of the A-1 with or without the A-3 pulley, sometimes with an additional partial flexor digitorum superficialis tendon resection (Van Heest et al. 1998). The outcome was generally good, with no recurrences and improved digital flexion and hand dexterity (Van Heest et al. 1998).

\section{Discussion and conclusion}

The aim of the current study was to systematically review the developmental and orthopaedic implications of Hurler's disease after treatment with HSCT. A considerable number of papers (32) with a total of 399 relevant patient reports were identified. Among these papers were only few prospective studies $(n=3)$ and no comparative studies. This has led to great variability in the scoring methods used, and carries the risk of a reporting bias. Another serious limitation of the currently published material was the relatively short follow-up period (on average 73.3 months after HSCT). Consequently, long term perspectives can not be given. Furthermore, the executed subgroup analyses were based on varying sample sizes, ranging from 7-170 patients. Nevertheless, the quantification of the prevalence and treatment of the various musculoskeletal complications, as currently given, may enhance the insights in the orthopaedic treatment of Hurler's disease.

The most frequently reported musculoskeletal manifestations of Hurler's disease after HSCT were odontoid hypoplasia, thoracolumbar kyphosis, genu valgum, hip dysplasia and carpal tunnel syndrome. Motor functioning was further compromised by reduced joint mobility, hand dexterity, motor skills, longitudinal growth, and neurological comorbidities. Although the positive effects of HSCT on the musculoskeletal manifestations of Hurler's disease were limited, improvements in joint mobility, motor skills, odontoid dysplasia, carpal tunnel syndrome and longitudinal growth were identified (Field et al. 1994; Hugh-Jones 1986; Weisstein et al. 2004; Fleming et al. 1998; Guffon et al. 1998; Hite et al. 2000). The improvements in joint mobility have been attributed to a reduction in GAG accumulation in the relatively well vascularised synovium, following the availability of donor enzyme in the blood (Breider et al. 1989). The improved joint mobility in addition to overall improvements in neuro-cognitive development might, in turn, explain the improved gross and fine motor skills of treated Hurler patients (Peters and Steward 2003). The etiology behind the improvement of the odontoid process deserves further attention, as it appears to be the only responsive endochondral bone (Hite et al. 2000; Tandon et al. 1996).

With regard to the positive effects of HSCT treatment, early timing seems favourable (Souillet et al. 2003; 
Bjoraker et al. 2006; Polgreen et al. 2008; Vellodi et al. 1997; Hite et al. 2000; Khanna et al. 2007). However, even early treatment cannot prevent dysostosis multiplex, presumably because many ossification defects have already developed prior to HSCT treatment. For example, kyphosis and hip dysplasia often appear at birth (Cleary and Wraith 1995; Ringden et al. 2006; Dusing et al. 2005; Malm et al. 2008a). Besides insufficient GAG clearance, further progression of the musculoskeletal abnormalities may be due to early irreversible changes both in the growth plate and the tendoligamentous complex responsible for load transfer and stability.

Although the natural course of the musculoskeletal manifestations of Hurler's disease after HSCT remains largely unknown, an active approach towards the orthopaedic management of these patients seems warranted, due to the irreversible and progressive nature of their deficiencies. Since various surgeries are often performed in the first decade of life, a combination of surgeries, for example of the hip and knee, is advocated (Odunusi et al. 1999). Unfortunately, prospective data on treatment outcome were lacking, making it impossible to determine possibly associated factors such as age, degree of deformity and weight bearing status at the time of treatment. Nevertheless, some general recommendations regarding the orthopaedic management and follow-up of Hurler patients may be formulated based on the currently published literature.

Cervical spine abnormalities are a major concern, since they might result in potentially life-threatening atlantoaxial instability and spinal cord compression, as has been frequently described in mucopolysaccharidosis type IV (MPS IV, Morquio's disease) and type VI (MPS VI, Maroteaux-Lamy) (Hughes et al. 1997; Thorne et al. 2001). In the Hurler population these symptoms were relatively rare. One of the reasons might be that odontoid dysplasia responded favourably to HSCT treatment (Hite et al. 2000; Tandon et al. 1996). Nevertheless, annual followup with MRI imaging should be considered. In order to treat atlantoaxial instability, it is currently not clear whether occipito-cervical fusions should be favoured above C1-C2 fusions.

Regarding the thoracolumbar kyphosis, various hypotheses on the pathogenesis have been posted. Swischuk (1970) suggested that it resulted from a combination of poor muscle tone, altered weight-bearing forces, growth abnormalities and disc herniation (Swischuk 1970). More recent findings point towards an important role of failure of ossification of the anterior superior aspect of the vertebral body (Field et al. 1994; Weisstein et al. 2004; Tandon et al. 1996). Bracing therapy might be considered especially in patients who are too young for surgery (Tandon et al. 1996; White and Harmatz 2010). Yet, the effectiveness remains largely unknown due to limited follow-up data and lack of information on the natural course of kyphosis in Hurler's disease. In the current literature, surgical intervention for progressive kyphosis was performed at a relatively young age (5.9 years). The decision to surgically intervene largely depended on the angle of kyphosis and the related risk of progression. The average pre-operative Cobbs angle of the Hurler patients $\left(58.8^{\circ}\right)$ was consistent with general guidelines for spinal fusion (Cobbs angle exceeding $60^{\circ}$ ) (Arlet and Schlenzka 2005). Both anterior and posterior short segment fusions might be considered. Although no adverse outcomes were reported for any of the techniques, personal communications imply that posterior fusion alone may lead to failure and the need of re-operation (White and Harmatz 2010). Clinical experience with anterior fusion, in contrast, seems promising, with no failures in a period of 10 years (personal communication with Dr. H. Noordeen, Great Ormond Street Hospital for Children, London, UK).

Hip dysplasia was found in the majority of Hurler patients. Yet, it should be noticed that the femoral head appeared well contained within the non-ossified lateral acetabular roof in many (Field et al. 1994; Taylor et al. 2008; Masterson et al. 1996). Nevertheless, nearly half of the patients underwent hip containment surgery. A typical feature of Hurler's disease appeared to be the failure of acetabular remodelling following an isolated femoral osteotomy. Consequently, an osteotomy of the pelvis (with or without additional femoral osteotomy) is favoured above an isolated femoral osteotomy in Hurler patients.

Progressive genu valgum occurred in the majority of patients and should be treated surgically because of the disabling consequences. Genu valgum was often treated by a temporary hemi-epiphyseodesis in the form of medial epiphyseal stapling. In children under 6 years, stapling as well as the 8-plate are difficult due to the small size of the epiphysis. In contrast, epiphyseal stapling may no longer be sufficient if the angular deformity of the knee is too large (Odunusi et al. 1999). Consequently, most patients are treated between 6-8 years of age. With respect to surgical intervention, a large percentage of adverse outcomes was observed due to the use of a suboptimal materials. After the introduction of new materials, adverse outcomes were no longer observed (Taylor et al. 2008; Odunusi et al. 1999).

With respect to carpal tunnel syndrome, an aggressive approach seems warranted. Early recognition is important, since surgical release can prevent adverse outcomes with muscle wasting, flexion contractures of the fingers, secondary bony changes and subsequent reduction in hand dexterity (Field et al. 1994; Souillet et al. 2003; Weisstein et al. 2004; Guffon et al. 1998; Vellodi et al. 1997; Van Heest et al. 1998; Khanna et al. 2007; Van Meir and De Smet 2005; Bona et al. 1994). Because classical symptoms such as numbness, tingling and nocturnal pain are often lacking 
(Van Heest et al. 1998), annual EMG testing is advisable. When a soft tissue release for CTS is performed, intraoperative inspection of the tendons of the fingers is indicated.

To conclude, stem cell transplantation has yielded enormous improvements in the therapy of Hurler's disease and patients are now surviving into adulthood. In order to benefit optimally from HSCT treatment, early timing is favourable. Consequently, the diagnostic delay should be reduced below the currently reported 9 months (Cleary and Wraith 1995). Since the skeletal abnormalities (especially the thoracolumbar kyphosis) account for $40 \%$ of the presenting signs and are often present at birth (Cleary and Wraith 1995), orthopaedic surgeons should play an important role in earlier diagnosis. Early surgical treatment is advocated and seems warranted, due to the limited response of the skeletal abnormalities to HSCT and their progressive and irreversible nature. However, prospective studies using standardised data collection are mandatory to further optimise the orthopaedic management of these patients.

Details of funding The authors confirm independence of sponsors.

Open Access This article is distributed under the terms of the Creative Commons Attribution Noncommercial License which permits any noncommercial use, distribution, and reproduction in any medium, provided the original author(s) and source are credited.

\section{References}

Aldenhoven M, Sakkers RJB, Boelens J, De Koning TJ, Wulffraat NM (2009) Musculoskeletal manifestations of lysosomal storage disorders. Ann Rheum Dis 68:1659-1665

Ard JL, Bekker A, Frempong-Boadu AK (2005) Anesthesia for an adult with mucopolysaccharidosis I. J Clin Anesth 17:624-626

Arlet V, Schlenzka D (2005) Scheuermann's kyphosis: Surgical management. Eur Spine J 14:817-827

Belani KG, Krivit W, Carpenter BL et al (1993) Children with mucopolysaccharidosis: perioperative care, morbidity, mortality, and new findings. J Pediatr Surg 28:403-408, discussion 408-10

Bjoraker KJ, Delaney K, Peters C, Krivit W, Shapiro EG (2006) Long-term outcomes of adaptive functions for children with mucopolysaccharidosis I (Hurler syndrome) treated with hematopoietic stem cell transplantation. J Dev Behav Pediatr 27:290-296

Bona I, Vial C, Brunet P, Couturier JC, Girard-Madoux M, Bady B, Guibaud P (1994) Carpal tunnel syndrome in Mucopolysaccharidoses. A report of four cases in child. Electromyogr Clin Neurophysiol 34:471-475

Breider MA, Shull RM, Constantopoulos G (1989) Long-term effects of bone marrow transplantation in dogs with mucopolysaccharidosis I. Am J Pathol 134:677-692

Cleary MA, Wraith JE (1995) The presenting features of mucopolysaccharidosis type IH (Hurler syndrome). Acta Paediatr 84:337-338
Dalvie SS, Noordeen MH, Vellodi A (2001) Anterior instrumented fusion for thoracolumbar kyphosis in mucopolysaccharidosis. Spine (Phila Pa 1976) 26:E539-E541

Dumas HM, Fragala MA, Haley SM, Skrinar AM, Wraith JE, Cox GF (2004) Physical performance testing in mucopolysaccharidosis I: a pilot study. Pediatr Rehabil 7:125-131

Dusing SC, Rosenberg A, Hiemenz JR, Piner S, Escolar M (2005) Gross and fine motor skills of children with Hurler syndrome (MPS-IH) post umbilical cord blood transplantation: a case series report. Pediatr Phys Ther 17:264-267

Dusing SC, Thorpe DE, Mercer VS, Rosenberg AE, Poe MD, Escolar ML (2007a) Temporal and spatial gait characteristics of children with Hurler syndrome after umbilical cord blood transplantation. Phys Ther 87:978-985

Dusing SC, Thorpe DE, Poe MD, Rosenberg AE, Mercer VS, Escolar ML (2007b) Gross motor development of children with hurler syndrome after umbilical cord blood transplantation. Phys Ther 87:1433-1440

Field RE, Buchanan JA, Copplemans MG, Aichroth PM (1994) Bonemarrow transplantation in Hurler's syndrome. Effect on skeletal development. J Bone Joint Surg Br 76:975-981

Fleming DR, Henslee-Downey PJ, Ciocci G, Romond EH, Marciniak E, Munn RK, Thompson JS (1998) The use of partially HLA-mismatched donors for allogeneic transplantation in patients with mucopolysaccharidosis-I. Pediatr Transplant 2:299-304

Guffon N, Souillet G, Maire I, Straczek J, Guibaud P (1998) Followup of nine patients with Hurler syndrome after bone marrow transplantation. J Pediatr 133:119-125

Hite SH, Peters C, Krivit W (2000) Correction of odontoid dysplasia following bone-marrow transplantation and engraftment (in Hurler syndrome MPS $1 \mathrm{H}$ ). Pediatr Radiol 30:464-470

Hobbs JR (1981) Bone marrow transplantation for inborn errors. Lancet 2:735-739

Hughes DG, Chadderton RD, Cowie RA, Wraith JE, Jenkins JPR (1997) MRI of the brain and craniocervical junction in Morquio's disease. Neuroradiology 39:381-385

Hugh-Jones K (1986) Psychomotor development of children with mucopolysaccharidosis type $1-\mathrm{H}$ following bone marrow transplantation. Birth Defects Orig Artic Ser 22:25-29

Kachur E, Del Maestro R (2000) Mucopolysaccharidoses and spinal cord compression: case report and review of the literature with implications of bone marrow transplantation. Neurosurgery 47:223-228, discussion 228-9

Khanna G, Van Heest AE, Agel J et al (2007) Analysis of factors affecting development of carpal tunnel syndrome in patients with Hurler syndrome after hematopoietic cell transplantation. Bone Marrow Transplant 39:331-334

Lucke T, Das AM, Hartmann H, Sykora KW, Donnerstag F, Schmid-Ott G, Grigull L (2007) Developmental outcome in five children with Hurler syndrome after stem cell transplantation: a pilot study. Dev Med Child Neurol 49:693-696

Malm G, Gustafsson B, Berglund G et al. (2008a) Outcome in six children with mucopolysaccharidosis type $\mathrm{IH}$, Hurler syndrome, after haematopoietic stem cell transplantation (HSCT). Acta Paediatr 97:1108-1112

Malm G, Lund AMY, Mansson J, Heiberg A (2008b) Mucopolysaccharidoses in the Scandinavian countries: Incidence and prevalence . Acta Paediatr Int J Paediatr 97:1773

Martins AM, Dualibi AP, Norato D et al. (2009) Guidelines for the Management of Mucopolysaccharidosis Type I. J Pediatr 155: S32-S46

Masterson EL, Murphy PG, O'Meara A, Moore DP, Dowling FE, Fogarty EE (1996) Hip dysplasia in Hurler's syndrome: orthopaedic management after bone marrow transplantation. J Pediatr Orthop 16:731-733 
Moore D, Connock MJ, Wraith E, Lavery C (2008) The prevalence of and survival in Mucopolysaccharidosis I: Hurler, Hurler-Scheie and Scheie syndromes in the UK. Orphanet J Rare Dis 3:24

Odunusi E, Peters C, Krivit W, Ogilvie J (1999) Genu valgum deformity in Hurler syndrome after hematopoietic stem cell transplantation: correction by surgical intervention. J Pediatr Orthop 19:270-274

Pastores GM, Arn P, Beck M et al. (2007) The MPS I registry: design, methodology, and early findings of a global disease registry for monitoring patients with Mucopolysaccharidosis Type I. Mol Genet Metab 91:37-47

Peters C, Steward CG (2003) Hematopoietic cell transplantation for inherited metabolic diseases: An overview of outcomes and practice guidelines. Bone Marrow Transplant 31:229-239

Polgreen LE, Tolar J, Plog M et al. (2008) Growth and endocrine function in patients with Hurler syndrome after hematopoietic stem cell transplantation. Bone Marrow Transplant 41:10051011

Polgreen LE, Plog M, Schwender JD et al. (2009) Short-term growth hormone treatment in children with Hurler syndrome after hematopoietic cell transplantation. Bone Marrow Transplant 44:279-285

Rebello G, Zilkens C, Dudda M, Matheney T, Kim Y (2009) Triple pelvic osteotomy in complex hip dysplasia seen in neuromuscular and teratologic conditions. J Pediatr Orthop 29:527-534

Ringden O, Remberger M, Svahn BM et al. (2006) Allogeneic hematopoietic stem cell transplantation for inherited disorders: experience in a single center. Transplantation 81:718-725

Silveri CP, Kaplan FS, Fallon MD, Bayever E, August CS (1991) Hurler syndrome with special reference to histologic abnormalities of the growth plate. CLIN ORTHOP RELAT RES: 305-311
Souillet G, Guffon N, Maire I et al. (2003) Outcome of 27 patients with Hurler's syndrome transplanted from either related or unrelated haematopoietic stem cell sources. Bone Marrow Transplant 31:1105-1117

Staba SL, Escolar ML, Poe M et al. (2004) Cord-blood transplants from unrelated donors in patients with Hurler's syndrome. N Engl J Med 350:1960-1969

Swischuk LE (1970) The beaked, notched, or hooked vertebra: its significance in infants and young children. Radiology 95:661-664

Tandon V, Williamson JB, Cowie RA, Wraith JE (1996) Spinal problems in mucopolysaccharidosis I (Hurler syndrome). J Bone Joint Surg Br 78:938-944

Taylor C, Brady P, O’Meara A, Moore D, Dowling F, Fogarty E (2008) Mobility in Hurler syndrome. J Pediatr Orthop 28:163168

Thorne JA, Javadpour M, Hughes DG, Wraith E, Cowie RA (2001) Craniovertebral abnormalities in type VI mucopolysaccharidosis (Maroteaux-Lamy syndrome). Neurosurgery 48:849-853

Van Heest AE, House J, Krivit W, Walker K (1998) Surgical treatment of carpal tunnel syndrome and trigger digits in children with mucopolysaccharide storage disorders. J Hand Surg Am 23:236-243

Van Meir N, De Smet L (2005) Carpal tunnel syndrome in children. J Pediatr Orthop B 14:42-45

Vellodi A, Young EP, Cooper A et al. (1997) Bone marrow transplantation for mucopolysaccharidosis type I: experience of two British centres. Arch Dis Child 76:92-99

Weisstein JS, Delgado E, Steinbach LS, Hart K, Packman S (2004) Musculoskeletal manifestations of Hurler syndrome: long-term follow-up after bone marrow transplantation. J Pediatr Orthop 24:97-101

White KK, Harmatz P (2010) Orthopedic management of mucopolysaccharide disease. J Pediatr Rehabil Med 3:47-56 